\title{
Erratum to "Effects of prepartum controlled-energy wheat straw and grass hay diets supplemented with starch or sugar on periparturient dairy cow performance and lipid metabolism" (J. Dairy Sci. 96:3050-3063)
}

\author{
N. B. Litherland, D. N. L. da Silva, W. P. Hansen, L. Davis, S. Emanuele, and H. Blalock
}

The section titled Selective Particle Consumption beginning on page 3059 contained some errors. The corrected section (corrections in bold) is shown below.

\section{Selective Particle Consumption}

One of the objectives of this study was to determine if LF reduces sorting (selective particle consumption) in a TMR. Given the differences in ingredients (WS vs. $\mathrm{GH}$ ), it is not surprising that particle size of the TMR were different among treatments (Table 3). In general, GH TMR had more particles $>\mathbf{1 9 . 0} \mathbf{~ m m}$, and the WS diets had more particles 19.0 to $8.0 \mathrm{~mm}$ in length and 8.0 to $1.2 \mathrm{~mm}$ in length. In addition, the adherence properties of LF may have agglomerated some of the fine particles to larger ones, reducing our ability to separate the fine material via PSPS.

During the prepartum period all cows selected against particles $>\mathbf{1 9 . 0} \mathbf{~} \mathbf{m m}$ in length and selected for particles $<\mathbf{1 . 1 8} \mathbf{~ m m}$ in length (Table 9). Compared with GH, cows fed WS sorted $(P<0.05)$ against particles $>\mathbf{1 9 . 0} \mathbf{~ m m}$ in length. Additionally, cows fed WS tended $(P=0.06)$ to sort for particles with a length of 8.0 to $1.18 \mathrm{~mm}$ in length. No effect of supplement on selective consumption of particles was observed. Cows were housed in individual tiestalls and had ad libitum access to feed; therefore, differences in sorting between treatments may be more subtle than cows housed and fed as a group. In addition, social dynamics may also influence feeding behavior of group-fed cows.

A greater $(P<0.001)$ mass of particles was retained on the top screen $(>19.0 \mathrm{~mm})$ for $\mathrm{LF}$ and tended $(P=$ 0.09 ) to have greater mass in the second screen (particles 19.0-8.0 mm) for LF compared with DF (Table 3) postpartum diets. The mass of particles 8.0 to 1.18 $\mathrm{mm}$ in length were similar between treatments, and DF resulted in more $(P<0.001)$ particles $<\mathbf{1 . 1 8} \mathbf{~ m m}$ in length than did LF. The postpartum selective particle consumption also showed that cows did very little measurable particle size sorting during the 24 -h period measured (Table 9). Cows fed DF supplement with their lactation TMR tended to consume more particles measuring >19.0 to $\mathbf{8 . 0} \mathbf{~ m m}$ in length compared with cows fed LF. This finding may be due to smaller particles adhering to the particles larger than $8.0 \mathrm{~mm}$ in length due to the agglomeration properties of the LF, resulting in inflated values for the top 2 screens of the PSPS. Differences in postpartum TMR particle distribution are also likely due to the physical form of the supplement (LF vs. DF). Sorting activity for small TMR particles $(<8 \mathrm{~mm})$ lowers rumen $\mathrm{pH}$ and increases pH range (DeVries et al., 2008). Molasses-based LF can affect particle distribution of corn silage-based lactation diets, reducing small particles $(<8 \mathrm{~mm})$ on the bottom pan of the PSPS, and increasing material $(>8$ to $<19$ $\mathrm{mm}$ ) on the middle screen of the PSPS. However, the extent of molasses-based liquid feed's effect on particle distribution is affected by forage type, processing, and overall diet particle distribution (Oelker et al., 2009). Consequently, reducing the proportion of fine particles in the TMR has the additional benefit of providing cows less opportunity to sort for fine particles, reducing the risk of suboptimal rumen $\mathrm{pH}$ and the resulting negative effects on feed utilization. In a field survey, Overton et al. (2008) demonstrated that the amount of particles 19.0 to $8.0 \mathrm{~mm}$ and $<\mathbf{8 . 0} \mathbf{~ m m}$ in length has a significant relationship to herd milk fat percent. This research demonstrates that a molasses-based liquid supplement reduces the amount of fines in the TMR and agglomerates small particles to larger ones, increasing the amount of material larger than $8.0 \mathrm{~mm}$ in the TMR particle distribution.

\section{REFERENCES}

Litherland, N. B., D. N. L. da Silva, W. P. Hansen, L. Davis, S. Emanuele, and H. Blalock. 2013. Effects of prepartum controlled-energy wheat straw and grass hay diets supplemented with starch or sugar on periparturient dairy cow performance and lipid metabolism. J. Dairy Sci. 96(5):3050-3063. 